Louisiana State University

LSU Digital Commons

8-19-2009

\title{
Variable temperature sensitivity of soil organic carbon in North American forests
}

\author{
Cinzia Fissore \\ Michigan Technological University \\ Christian P. Giardina \\ USDA Forest Service Pacific Southwest Research Station \\ Christopher W. Swanston \\ USDA Forest Service \\ Gary M. King \\ Louisiana State University \\ Randall K. Kolka \\ USDA Forest Service
}

Follow this and additional works at: https://digitalcommons.Isu.edu/biosci_pubs

\section{Recommended Citation}

Fissore, C., Giardina, C., Swanston, C., King, G., \& Kolka, R. (2009). Variable temperature sensitivity of soil organic carbon in North American forests. Global Change Biology, 15 (9), 2295-2310. https://doi.org/ 10.1111/j.1365-2486.2009.01903.x

This Article is brought to you for free and open access by the Department of Biological Sciences at LSU Digital Commons. It has been accepted for inclusion in Faculty Publications by an authorized administrator of LSU Digital Commons. For more information, please contact ir@lsu.edu. 


\title{
Variable temperature sensitivity of soil organic carbon in North American forests
}

\author{
CINZIA FISSORE*1, CHRISTIAN P. GIARDINA $\dagger$, CHRISTOPHER W. SWANSTON \\ GARY M. KING§ and RANDALLK. KOLKA \\ *School of Forest Resources and Environmental Science, Michigan Technological University, 1400 Townsend Drive, Houghton, MI \\ 49931, USA, †USDA Forest Service, Pacific Southwest Research Station, Institute of Pacific Islands Forestry, 60 Nowelo Drive, \\ Hilo, HI 96720, USA, ‡USDA Forest Service, Northern Research Station, 410 MacInnes Drive, Houghton, MI 49931, USA, \\ §Department of Biological Science, Louisiana State University, Baton Rouge, LA 70803, USA, $\uparrow$ USDA Forest Service, Northern \\ Research Station, 1831 Hwy. 169 E., Grand Rapids, MN 55744, USA
}

\begin{abstract}
We investigated mean residence time (MRT) for soil organic carbon (SOC) sampled from paired hardwood and pine forests located along a $22^{\circ} \mathrm{C}$ mean annual temperature (MAT) gradient in North America. We used acid hydrolysis fractionation, radiocarbon analyses, long-term laboratory incubations (525-d), and a three-pool model to describe the size and kinetics of the acid insoluble C (AIC), active and slow SOC fractions in soil. We found that active SOC was $2 \pm 0.2 \%$ (mean \pm SE) of total SOC, with an MRT of $33 \pm 6$ days that decreased strongly with increasing MAT. In contrast, MRT for slow SOC and AIC ( $70 \pm 6 \%$ and $27 \pm 6 \%$ of total SOC, respectively) ranged from decades to thousands of years, and neither was significantly related to MAT. The accumulation of AIC (as a percent of total SOC) was greater in hardwood than pine stands $(36 \%$ and $21 \%$, respectively) although the MRT for AIC was longer in pine stands. Based on these results, we suggest that the responsiveness of most SOC decomposition in upland forests to global warming will be less than currently modeled, but any shifts in vegetation from hardwood to pine may alter the size and MRT of SOC fractions.
\end{abstract}

Keywords: carbon quality, $Q_{10}$, radiocarbon, SOC decomposition, SOC fractionation, stable C, temperate forests

Received 14 September 2008; revised version received 21 January 2009 and accepted 27 January 2009

\section{Introduction}

The impact of climate change on the carbon (C) balance of terrestrial ecosystems depends on changes in the total quantity and quality of detrital $C$ entering soils as well as changes in the rate at which stable soil organic carbon (SOC) is decomposed by heterotrophic organisms and released back to the atmosphere as carbon dioxide $\left(\mathrm{CO}_{2}\right)$. If the heterotrophic decomposition rate of most SOC is enhanced by warming, then the $\mathrm{CO}_{2}$ sink strength of soils may decline in a warmer world, resulting in a positive feedback to global temperatures (Jenkinson et al., 1991; Schimel et al., 1994). In contrast, if

Correspondence: Cinzia Fissore, tel. + 1612625 3125, fax + 1612 625 2208, e-mail: fisso001@umn.edu

${ }^{1}$ Present address: Department of Soil, Water, and Climate, University of Minnesota, 439 Borlaug Hall, 1991 Upper Buford Circle, Saint Paul, MN 55108, USA. the decomposition of most SOC is negligibly responsive to temperature (Giardina \& Ryan, 2000), forest soils may continue to act as a net sink for atmospheric $\mathrm{CO}_{2}$, and thus provide a negative feedback to increased atmospheric $\mathrm{CO}_{2}$ concentration (Holland et al., 2000). Critically, available information is inadequate to assess with confidence the likelihood of either outcome (Davidson \& Janssens, 2006).

Studies have documented a wide range of SOC decomposition responses to temperature (Wedin \& Pastor, 1993; Townsend et al., 1995; Giardina \& Ryan, 2000; Fang et al., 2005; Davidson \& Janssens, 2006; Conant et al., 2008). Short-term lab incubations indicate similar temperature sensitivity for both active and less active SOC (e.g., Fang et al., 2005), but these incubations are not sufficiently long to describe the decomposition responses of stable SOC. Mathematical models also based on short-term incubations have shown that it is theoretically possible to have an increase in the 
temperature sensitivity of stable SOC compared with active SOC (Knorr et al., 2005), but these models require important assumptions about the distribution and activation energies of SOC across fractions - assumptions that have yet to be validated. In contrast, some studies suggest that stabilization of SOC may increase with global warming (Dalias et al., 2001; Thornley \& Cannell, 2001; Fissore et al., 2008). In line with these results, other modeling efforts point to a smaller than predicted temperature response of SOC decomposition (Ise \& Moorcroft, 2006).

Indirect effects of climate change on SOC MRT may originate also from variations in tree species composition and distribution (Sykes \& Prentice, 1996; Xu et al., 2007). Efforts to quantify the links between the chemical characteristics of inputs and accumulation of SOC with different MRT have yielded diverse outcomes (Melillo et al., 1989; Quideau et al., 2001). Based on evidence that litter mass loss is greater for simple substrates (Melillo et al., 1982), the $C: N$ and lignin : $N$ of inputs to soil have been used to predict SOC quality. However, inherent chemical recalcitrance of inputs to soil appears to correlate with only the initial phase of $\mathrm{C}$ decomposition (von Lützov et al., 2006), and the reciprocal role played by $\mathrm{C}$ and $\mathrm{N}$ in SOC stabilization may be more complex than previously suggested (as summarized by Sollins et al., 2007; see also Fog, 1988; Swanston et al., 2004; Kleber et al., 2007). Further, there is growing evidence that higher quality litter (e.g. low $\mathrm{C}: \mathrm{N}$ or low lignin : N) may have long-term stabilizing effects on SOC, resulting in accumulation of SOC with low MRT (Giardina et al., 2001). For example, protein-like C compounds consistently are found in stable SOC (Lorenz et al., 2007), while lignin-like molecules represent only a minor component. Limited lignin accumulation in stable SOC fractions suggests a faster decomposition of lignin than previously hypothesized and the concomitant contribution to SOC of other organic molecules, such as alkyl-C compounds that are in part of microbial origin (Mikutta et al., 2006; Lorenz et al., 2007). Overall, evidence indicates that $\mathrm{N}$ has inhibitory effects on microbial enzymatic activity, reacts with $\mathrm{C}$ compounds to form stable organic matter, and can facilitate the binding of organic matter to soil clay minerals (Prescott et al., 2000; Berg \& Meentemeyer, 2002; Russell et al., 2007), all of which can contribute to SOC stabilization (Magill et al., 1997). Clearly, the nature of the relationship between litter quality and SOC quality remains uncertain.

Uncertainty in controls over soil C process rates may also be compounded by unclear terminology. Throughout this paper we refer to three fractions of SOC: acid insoluble C (AIC), slow and active SOC. We define AIC as the residue that is insoluble in $6 \mathrm{~N} \mathrm{HCl}$ following a series of physical and chemical fractionation steps. The resulting SOC fraction includes chemically recalcitrant substrates and $\mathrm{C}$ that is strongly stabilized by the mineral phase. The AIC fraction may be chemically or physically protected by mechanisms similar to those protecting the 'stable' $\mathrm{C}$ fraction isolated using similar approaches (e.g., acid hydrolysis of bulk soil, density fractionation). The $\mathrm{CO}_{2}$ evolved during incubation studies under controlled conditions represents the biological fractionation of active and, depending on duration of the incubation, part of the slow SOC stored in soil (Townsend et al., 1997; Collins et al., 2000; Paul et al., 2001). Overall, extended lab incubations are consistent with other methods in isolating active SOC (McLauchlan \& Hobbie, 2004), which is quantified through analysis of $\mathrm{CO}_{2}$ efflux from incubated soils and is mathematically defined as the SOC released early in the incubation. The slow SOC fraction is less labile with mean residence times (MRT) intermediate between active and the AIC fraction, and is estimated by difference (see also 'Methods').

Despite complications relating to terminology, separation of SOC into conceptual fractions with different MRT is useful for both describing the dynamics of SOC (Paul et al., 2006), and also predicting the response of SOC to changing temperature (von Lützov et al., 2007). For these reasons, we relied on $C$ fractionation and radiocarbon analysis, laboratory incubations, and a well-established three-pool first-order decomposition model (Paul et al., 2001, 2006) to provide a quantitative characterization of AIC, slow and active SOC fractions and their decomposition rates.

The MRT for stable SOC ranges from hundreds to even thousands of years (Trumbore et al., 1996; Torn et al., 1997). Hydrolysis in $\mathrm{HCl}$ isolates a residue that is measurably older than the hydrolysable material (Leavitt et al., 1997). This approach was used in agricultural and forest soils of North America to separate a fraction of SOC that was on average 1300-year older than total SOC (Paul et al., 2001). Chemical analyses showed that the SOC fraction that is insoluble in concentrated $\mathrm{HCl}$ is composed mainly of waxes and longchain alkyl compounds (Rovira \& Vallejo, 2002; Paul et al., 2006), lignin-like compounds (Collins et al., 2000), and other aromatic compounds that are resistant to degradation (Paul \& Clark, 1996). Easily degradable compounds such as soluble carbohydrates, proteins, and amino acids are typically susceptible to solubilization in presence of acids (Barriuso et al., 1987).

Forests store large quantities of SOC (Jobbagy \& Jackson, 2000) and continue to be a net sink of atmospheric C (Fan et al., 1998), yet few studies have examined the relationships between mean annual temperature (MAT), vegetation cover, and SOC MRT. Our 
study builds on pioneering work across elevation (Trumbore et al., 1996) and continental (Paul et al., 2001) gradients but relies on a highly controlled MAT gradient across North America (Fissore et al., 2008), where surface soil texture, growing season site water balance, vegetation cover (paired sites of Pinus or hardwood dominated forest), and stand maturity (well past canopy closure) were similar. We used this paired gradient to isolate the effects of temperature and vegetation on SOC fraction size and MRT and to test several hypotheses about SOC response to temperature.

Our first hypothesis was that despite higher decomposition rates for active SOC at warm sites, decomposition rates for AIC and slow SOC would not be temperature limited, and so the MRT of these SOC fractions would be insensitive to MAT. Further, we hypothesized that increasing MAT shifts the distribution of SOC from active to stable fractions because the temperature response of soil chemical-physical reactions are stronger than that of microbial enzymatic processes and so warming results in a net increase in the transfer of $\mathrm{C}$ compounds from unprotected to protected sites (Thornley \& Cannell, 2001). Also, we used this MAT gradient to ask questions about how temperature interacts with contrasting surface litter types (pine vs. hardwood) to affect SOC fraction size and MRT. We hypothesized that, although high-quality hardwood litter initially decomposes more rapidly than low-quality pine litter, a higher proportion of stable SOC accumulates in hardwood than in pine soils because of the long-term inhibitory effects on SOC decomposition exerted by N (Berg, 2000; Giardina et al., 2001; Berg \& Meentemeyer, 2002) and because N contributes to the formation of the structures of stable $\mathrm{C}$ compounds (Fog, 1988; Russell et al., 2007).

This study addresses a critical knowledge gap regarding how SOC fraction size and MRT respond to changes in MAT and vegetation by relying on a sampling design that represents a space for time substitution. By sampling along a gradient in MAT, our results highlight longer-term changes that integrate decades to centuries long climate effects on SOC process rates across sites. This approach provides less information on short-term responses to climate change. None-the-less, coupling this MAT gradient with radiocarbon analyses, we were able to estimate the size and MRT of the AIC fraction under field conditions, where resulting data integrate the in situ effects of MAT, substrate supply, and vegetation on SOC stabilization. We quantified the dynamics of active $\mathrm{C}$ using a lab-based approach with results scaled to the field using paired incubations at two temperatures to develop temperature response functions. The field-based AIC fraction data and the labbased active SOC fraction data were combined to model the size and kinetics of AIC, slow and active SOC fractions along our continental-scale MAT gradient.

\section{Methods}

\section{Site description and soil characteristics}

Soils used in this study were sampled from 26 sites located in six bioclimatic regions spanning a $22^{\circ} \mathrm{C}$ MAT gradient in North America (Table 1). Across regions, mean annual precipitation (MAP) increased with MAT. Higher evapotranspiration at warm sites resulted in relatively constant calculated growing season water balance across the gradient. All but the Michigan sites were located in Experimental Forests of the USDA National Forest Service or of Universities. Closed-canopy stands were mature for the region. Hardwood species composition was similar along the gradient, with the exception of the coldest Colorado site, where maple was not present. We sampled even-aged aspen stands in Colorado and also Minnesota, where we also sampled sugar maple dominated forests. Pine species composition varied in relation to climate. Stand history and climate data were available for all locations. Most sites have always been in forest, with two Michigan sites and two Georgia sites having a history of land clearing. For these sites, forest cover at the time of sampling had been in place for at least 70 years. Detailed site description is provided by Fissore et al. (2008) and is summarized in Tables 1 and 2.

We collected soils at fixed depth increments without consideration of soil horizons. We sampled the top $20 \mathrm{~cm}$ of the mineral soil after removing forest floor material by using a $\varnothing 10 \mathrm{~cm}$ soil auger. Immediately after sampling, soils were shipped overnight in coolers to the USDA Forest Service Lab in Houghton, MI where we separated roots and rocks from fresh soil $(<2$ days from sampling) using a $2 \mathrm{~mm}$-mesh sieve. Soils were then dried at $30{ }^{\circ} \mathrm{C}$ in a forced air oven and processed for chemical-physical characterization, incubation, and archiving.

Soils were coarse-textured with $\mathrm{pH}$ varying between 4.3 and 6.1 (Table 2). Proportion of expandable clay minerals, $\mathrm{pH}$, cation exchange capacity (CEC), and SOC content were all negatively related to MAT. Soil texture was finer and SOC content was generally higher in hardwood than pine sites (Fissore et al., 2008).

\section{Quantifying AIC}

The AIC fraction was isolated from other fractions by chemical and physical fractionation including acid hydrolysis (Loya et al., 2003) followed by radiocarbon analyses (Torn et al., 2002). These methods allowed us 


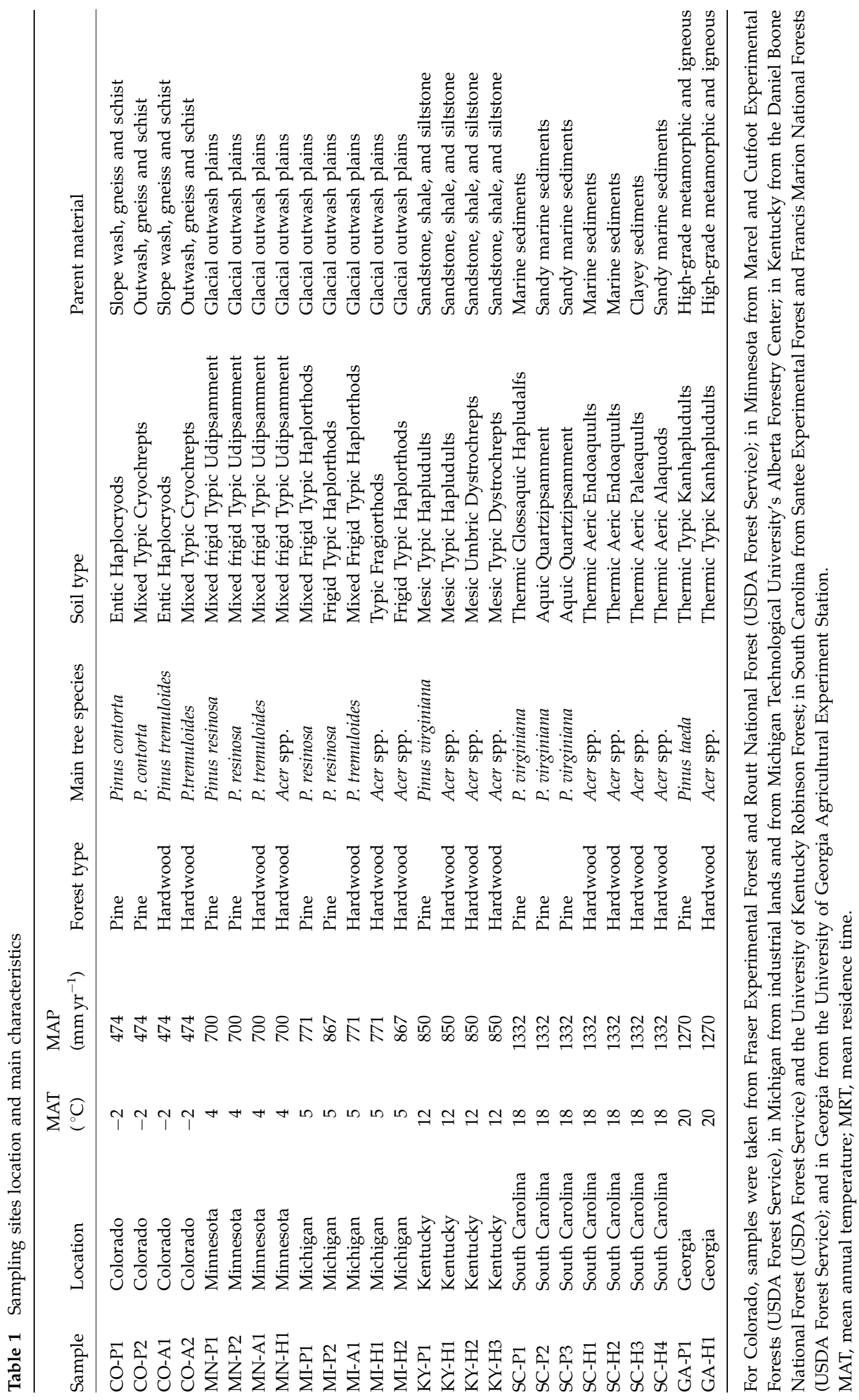

Published 2009

This article is a US Government work and is in the public domain in the USA, Global Change Biology, 15, 2295-2310 
Table 2 Main soil chemical and physical characteristics of soils sampled across the $22^{\circ} \mathrm{C}$ MAT gradient

\begin{tabular}{|c|c|c|c|c|c|c|}
\hline Sample & Texture & $\begin{array}{l}\text { Clay } \\
(\%)\end{array}$ & $\mathrm{pH}$ & $\begin{array}{l}\text { CEC } \\
\left(\text { cmolc kg }^{-1}\right)\end{array}$ & $\mathrm{C}(\%)$ & $N(\%)$ \\
\hline CO-P1 & Sandy-loam & 8.3 & 5.8 & 6.8 & 2.20 & 0.09 \\
\hline $\mathrm{CO}-\mathrm{P} 2$ & Sandy-loam & 12.0 & 5.6 & 10.5 & 2.64 & 0.10 \\
\hline CO-A1 & Sandy-loam & 10.0 & 6.1 & 26.4 & 8.07 & 0.53 \\
\hline CO-A2 & Sandy-loam & 7.0 & 6.1 & 10.6 & 3.48 & 0.11 \\
\hline MN-P1 & Sandy-loam & 4.5 & 5.6 & 4.5 & 1.45 & 0.07 \\
\hline MN-P2 & Loamy-sand & 3.0 & 5.3 & 3.2 & 1.05 & 0.05 \\
\hline MN-A1 & Sandy-loam & 8.5 & 5.7 & 4.8 & 1.60 & 0.09 \\
\hline MN-H1 & Sandy-loam & 8.0 & 5.8 & 6.9 & 1.93 & 0.11 \\
\hline MI-P1 & Sand & 1.0 & 4.9 & 1.7 & 1.07 & 0.05 \\
\hline MI-P2 & Sand & 2.0 & 4.7 & 1.6 & 1.33 & 0.07 \\
\hline MI-A1 & Loamy-sand & 3.0 & 5.0 & 2.0 & 1.34 & 0.07 \\
\hline MI-H1 & Sandy-loam & 4.0 & 4.9 & 5.5 & 3.38 & 0.24 \\
\hline MI-H2 & Sand & 2.0 & 4.8 & 2.2 & 1.62 & 0.09 \\
\hline KY-P1 & Sandy-loam & 10.0 & 4.4 & 3.2 & 2.24 & 0.06 \\
\hline KY-H1 & Loam & 16.0 & 5.7 & 6.6 & 2.10 & 0.16 \\
\hline KY-H2 & Loam & 15.0 & 4.8 & 3.7 & 2.34 & 0.14 \\
\hline KY-H3 & Sandy-loam & 8.0 & 4.6 & 2.1 & 1.22 & 0.05 \\
\hline SC-P1 & Loamy-sand & 4.0 & 4.8 & 2.1 & 1.74 & 0.06 \\
\hline SC-P2 & Sand & 3.5 & 4.9 & 1.3 & 0.88 & 0.03 \\
\hline SC-P3 & Sand & 1.0 & 4.7 & 1.4 & 1.37 & 0.04 \\
\hline SC-H1 & Loam & 20 & 4.4 & 5.8 & 2.06 & 0.09 \\
\hline $\mathrm{SC}-\mathrm{H} 2$ & Loam & 16 & 4.3 & 3.5 & 1.76 & 0.07 \\
\hline SC-H3 & Sandy-loam & 13 & 4.6 & 2.8 & 1.47 & 0.06 \\
\hline SC-H4 & Sand & 3.0 & 4.8 & 1.9 & 1.24 & 0.05 \\
\hline GA-P1 & Sand & 3.5 & 4.5 & 1.3 & 1.00 & 0.04 \\
\hline GA-H1 & Sandy-loam & 13 & 5.2 & 3.6 & 2.50 & 0.17 \\
\hline
\end{tabular}

More details on site characteristics and soil analyses can be found in Fissore et al. (2008).

MAT, mean annual temperature; CEC, cation exchange capacity.

to quantify both the size and MRT of the AIC fraction. Due to the high cost of radiocarbon analyses, we limited analyses to a subset of 16 of the 26 soils samples from the MAT gradient.

Fractionation for AIC consisted of removing waterextractable SOC through agitation in DI water for $24 \mathrm{~h}$, followed by filtration through a $0.45 \mu \mathrm{m}$ glass filter membrane using a pump-vacuum system. The nonextracted soil material captured on the membrane was scraped off into specimen cups and dried at $60^{\circ} \mathrm{C}$. This material was then mixed with a solution of $1 \mathrm{M} \mathrm{NaCl}$ to float and remove particulate matter. The remaining soil was then rinsed several times though a fiber membrane with deionized water and then centrifuged to remove excess of salt (Loya et al., 2003). The separated soil material was again dried at $60^{\circ} \mathrm{C}$ and then analyzed to assess \%C (Costech Elemental Combustion System 4010 Mass Spectrometer, Costech, Valencia, CA, USA). Using $5 \mathrm{~g}$ of this soil residue for each of the 16 samples, we removed any identifiable fragments of plant material by hand under a microscope $(\times 20$ magnification, and $\sim 50 \mathrm{~h}$ per sample). Particular attention was paid to removing only identifiable plant material. Following microscope work, the soil was acidified in $6 \mathrm{~N} \mathrm{HCl}$ for 12-h at $116^{\circ} \mathrm{C}$ to separate acid-soluble and acid-insoluble SOC fractions. The solution of soil residue and acid was then allowed to cool overnight (approximately $12 \mathrm{~h}$ ) to ambient temperature and subsequently rinsed with deionized water and then decanted into a pumpvacuum system that passed the water and soil mixture through a glass fiber membrane to isolate AIC. This was repeated until no remaining soil was observed. The glass fiber carrying the residue was then transferred into Al-tins of known weight and oven dried at $60{ }^{\circ} \mathrm{C}$. The residue was then scraped off the fiber membrane and analyzed to assess \% $\mathrm{C}$ that is AIC (Costech Elemental Combustion System 4010 Mass Spectrometer).

AIC fraction and the paired bulk soil (total SOC) for the 16 samples were analyzed for radiocarbon content by accelerator mass spectrometry at Lawrence Livermore National Laboratory. Sample preparation consisted of combustion in presence of $\mathrm{CuO}$ and $\mathrm{Ag}$ followed by reduction of $\mathrm{CO}_{2}$ in presence of $\mathrm{H}_{2}$ and a $\mathrm{Fe}$ catalyst to produce graphite (Vogel et al., 1984). The ${ }^{14} \mathrm{C}$ analysis was then conducted using graphite targets (Vogel, 1992). Radiocarbon data are reported as $\Delta^{14} \mathrm{C}$, which refers to the deviation in parts per thousand from the ${ }^{14} \mathrm{C} /{ }^{12} \mathrm{C}$ of oxalic acid standard and samples were corrected for fractionation effects to a forest $\delta^{13} \mathrm{C}$ value of -25\%o (Stuiver \& Polach, 1977).

\section{Quantifying active and slow SOC fractions}

Long-term incubations (525 days) allowed us to quantify the kinetics of active SOC on soil samples used for the radiocarbon analyses plus an additional 10 soils samples from across the MAT gradient and vegetation types to improve our estimates of total loss and temperature sensitivity $\left(Q_{10}\right)$ of SOC decomposition. These incubations were conducted on two identical sets of 26 soil samples at lab incubation temperatures (LIT) of $10{ }^{\circ} \mathrm{C}$ (LIT10) and $30^{\circ} \mathrm{C}$ (LIT30). We selected LIT10 because this temperature corresponds to the average MAT across our sites and characterizes growing season soil temperatures at the coldest sites, while LIT30 represents growing season soil temperatures at the warm-end of the gradient, and is also a commonly used temperature in previous incubation studies (Winkler et al., 1996; Collins et al., 2000; Paul et al., 2006).

For each soil sample, $30 \mathrm{~g}$ of dry soil were placed into $120 \mathrm{~mL}$ specimen cups, brought to moisture corresponding to $60 \%$ of water holding capacity (WHC), and then incubated in 1-L mason jars. Each jar was 
provided with a lid and septum for gas collection. Throughout the incubation, samples were maintained moist at $60 \pm 5 \%$ of WHC and at constant temperature $\left(10\right.$ or $\left.30^{\circ} \mathrm{C}\right)$ in Precision 815 low temperature incubators (Winchester, VA). We determined soil WHC by saturating a known amount of $30^{\circ} \mathrm{C}$-dry soil that was previously brought to a specific bulk density of $1 \mathrm{mg} \mathrm{m}^{-3}$ (Elliott et al., 1994). The saturated soil, after free water was allowed to drain, represented $100 \%$ of WHC, while dry soil represented $0 \%$ of WHC.

During the 525 days incubation, we periodically measured the $\mathrm{CO}_{2}$ efflux over a 24-h period for each soil sample. Before each gas sampling event, we flushed the samples with ambient air for 30-min, sealed the jars, and immediately sampled a subset of 5-10 samples for time zero head space gas measurements. Samples in the sealed jars were then incubated at the predefined LIT10 or LIT30 for 24-h and head space gas was sampled a second time for Gas Chromatograph $\left(\mathrm{CO}_{2}\right)$ analysis (Agilent 6890 Gas Chromatograph, Agilent Inc., Palo Alto, CA, USA). Gas sampling utilized a $50 \mathrm{~mL}$ gas-tight syringe by first drawing and plunging the syringe three times to guarantee homogeneous gas sampling. Each sample was injected into 4-mL gas-tight vials and analyzed within 8-h of collection. Time zero gas measurements were used as baseline ambient $\left[\mathrm{CO}_{2}\right]$ to be subtracted from head space $\left[\mathrm{CO}_{2}\right]$ at the end of the 24-h period to calculate efflux rates. Cumulative SOC loss was obtained from the conversion of $\mathrm{CO}_{2}$ efflux rates into percent of the initial soil $\mathrm{C}$ lost during the incubation. An initial 30-day trial of our experiment showed high reproducibility $\left(r^{2}=0.96, P<0.01, n=34\right)$, and analyses over $24 \mathrm{~h}$ showed strong linearity of efflux rates $\left(r^{2}=0.99 ; P<0.01 ; n=10\right.$; Fissore et al., 2008). We calculated values of temperature sensitivity $\left(Q_{10}\right)$ by comparing the two LITs as:

$$
Q_{10}=\left(\frac{R_{1}}{R_{2}}\right) \mathrm{e}^{\left(\frac{10}{\operatorname{LIT30-LT10}}\right)},
$$

where $R_{1}$ and $R_{2}$ equal SOC respiration rates at LIT30 and LIT10, respectively. For comparison and following Conant et al. (2008), we also calculated $Q_{10}$ based on the time required for a known amount of SOC to decompose.

\section{MRT and kinetics of SOC fractions}

For a subset of 16 soil samples (Table 3), we evaluated the size and kinetics of the three SOC pools according to a three-pool first order decomposition model (Collins et al., 2000; Paul et al., 2001) as follows:

$$
C_{\mathrm{t}(t)}=C_{\mathrm{a}} \mathrm{e}^{-k a(t)}+C_{\mathrm{s}} \mathrm{e}^{-k s(t)}+C_{\mathrm{r}} \mathrm{e}^{-k r(t)},
$$

where $C_{\mathrm{t}(t)}$ is the total SOC at time $t ; C_{\mathrm{a}}, C_{\mathrm{s}}$, and $C_{\mathrm{r}}$ represent the $C$ mass in the active, slow and AIC fractions, respectively; $k a, k s$, and $k r$ are the rates of decomposition. We then solved for the corresponding model:

$$
\mathrm{d} C / \mathrm{dt}=C_{\mathrm{a}} k a \mathrm{e}^{(-k a t)}+C_{\mathrm{s}} k s \mathrm{e}^{(-k s t)}+C_{\mathrm{r}} k r \mathrm{e}^{(-k r t)},
$$

where $C_{a}, k a$, and $k s$ were obtained through the analysis of the $\mathrm{CO}_{2}$ efflux rates from the decomposition study by curve fitting, while $C_{\mathrm{s}}$ was constrained as $C_{\mathrm{s}}=\left(C_{\mathrm{tot}}-\left(C_{\mathrm{a}}+C_{\mathrm{r}}\right)\right) ; C_{\mathrm{r}}$ and $k r$ were derived from acid hydrolysis (Leavitt et al., 1997) and radiocarbon analysis. Specifically, calculation of field-based radiocarbonderived MRT of AIC was accomplished using a timedependent steady-state model (Trumbore et al., 1995; Gaudinski et al., 2000; Torn et al., 2002). The MRT of active and slow SOC was obtained as $1 / k$ from lab incubation curves. For lab-derived SOC fractions (active and slow), MRT values were scaled to field MAT by multiplying (lab) MRT by the following conversion factor:

$$
Q_{10} \times \mathrm{e}^{\left(\frac{\mathrm{LT10-MAT}}{\mathrm{LT} 30}\right),}
$$

where MAT is site-specific. Hereafter active and slow MRT will always refer to field-scaled MRT. This adjustment allows comparison of ${ }^{14} \mathrm{C}$-based MRT, which reflect field conditions, to incubation-based MRT. In contrast to earlier studies (Collins et al., 2000; HaileMariam et al., 2000; Paul et al., 2001), we did not rely on an assumed $Q_{10}$ of 2.0 to scale lab results to the field, but instead adopted the average $Q_{10}$ calculated from our incubation experiments $\left(Q_{10}=1.5\right)$. Using an assumed $Q_{10}$ of 2 instead of the incubation-derived $Q_{10}$ of 1.5 to scale MRT from the lab to the field results in on average a twofold increase in active SOC MRT (MRT $=70 \pm 15$ with $Q_{10}=2$ vs. MRT $=33 \pm 6$ with $Q_{10}=1.5$ ), with larger increases at cold sites and smaller at warm sites. Critically, these changes in relationship of active SOC MRT with MAT (with $Q_{10}=2$, MRT active $\mathrm{SOC}=-6.5 \mathrm{MAT}+134.4 ; r^{2}=0.79 ; P<0.05 ; n=16$ vs. $Q_{10}=1.5$, where MRT active $\mathrm{SOC}=-2.5 \mathrm{MAT}+57.1$; $\left.r^{2}=0.82, P<0.05\right)$ do not alter our conclusions about the relationship between AIC MRT and MAT because the AIC MRT is derived from radiocarbon analyses. For the slow SOC fraction, using a $Q_{10}$ of 2 in the model would actually dampen the effect of MAT on MRT.

\section{Statistical analysis}

In each of the six bioregions examined in this study, we sampled between two to six replicate stands, for a total of 26 sites. Each replicate stand sample was composed of three aggregated subsamples. Replicated stands were considered true replicates because of geographic location and vegetation type. Differences in vegetation type 


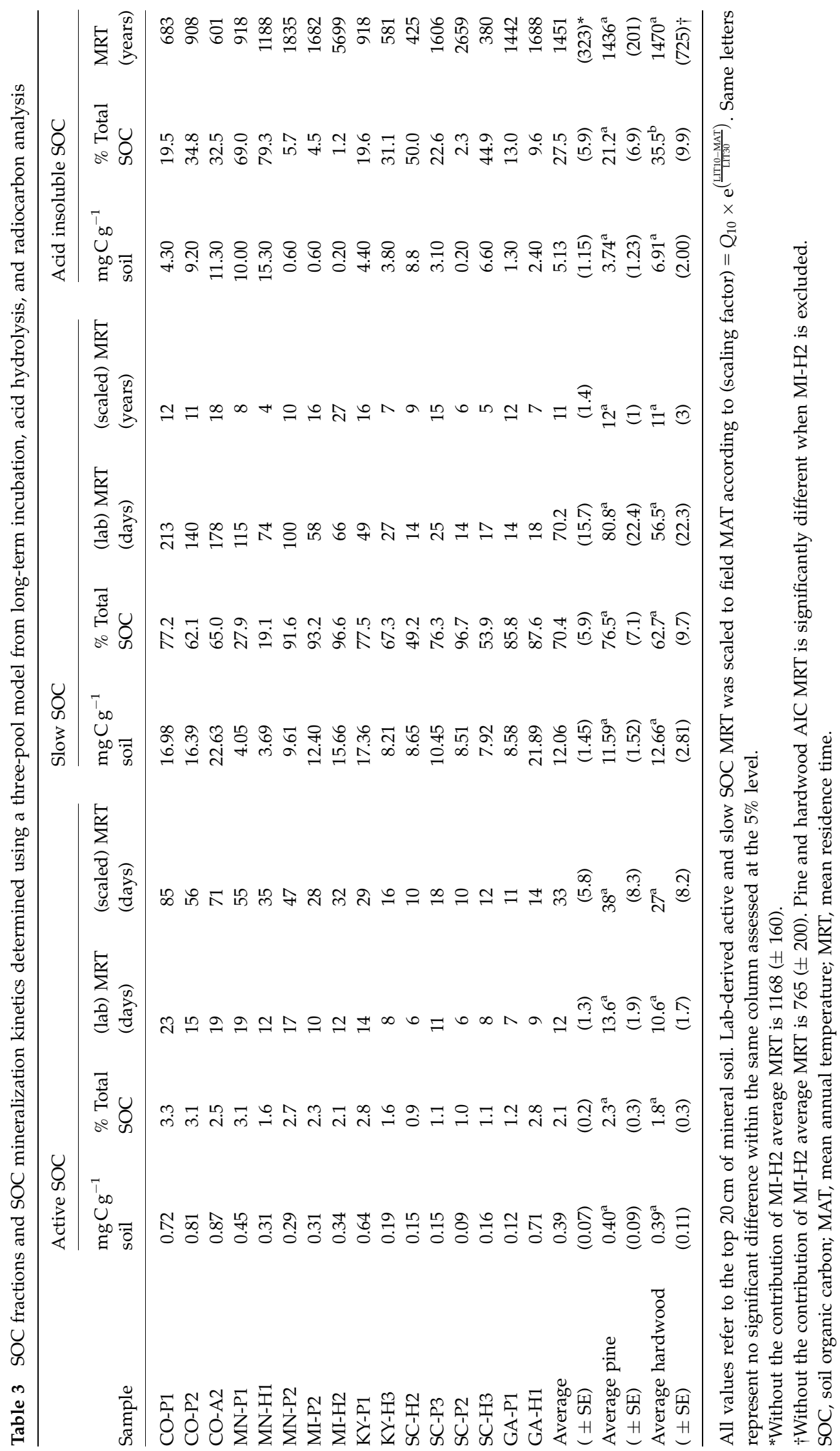


within each region (paired hardwood and pine) were used as a qualitative variable for the regression analyses. We used simple linear regression to evaluate the relationship between MAT and the size and MRT of AIC, slow and active SOC; multiple linear regression to investigate the relationship of different soil characteristics with SOC decomposition; and $t$-test analyses to assess differences in SOC loss and site characteristics between vegetation types. We relied on nonlinear regression to describe the relationship between AIC content and delta $\Delta^{14} \mathrm{C}$ (SPSS 15.0, SPSS Inc., Chicago, IL, USA). In all cases significance was assessed by $\alpha=0.05$.
The three-pool SOC model was conducted through nonlinear regression of the SOC decomposition curve at LIT30 of soil samples (PROC NLIN METHOD= MARQUARDT, SAS 9.1, 1995).

\section{Results}

\section{SOC quality across the MAT gradient}

AIC. Size and MRT of the AIC fractions were obtained through chemical-physical fractionation and radiocarbon analysis of bulk sieved soils. Resulting information
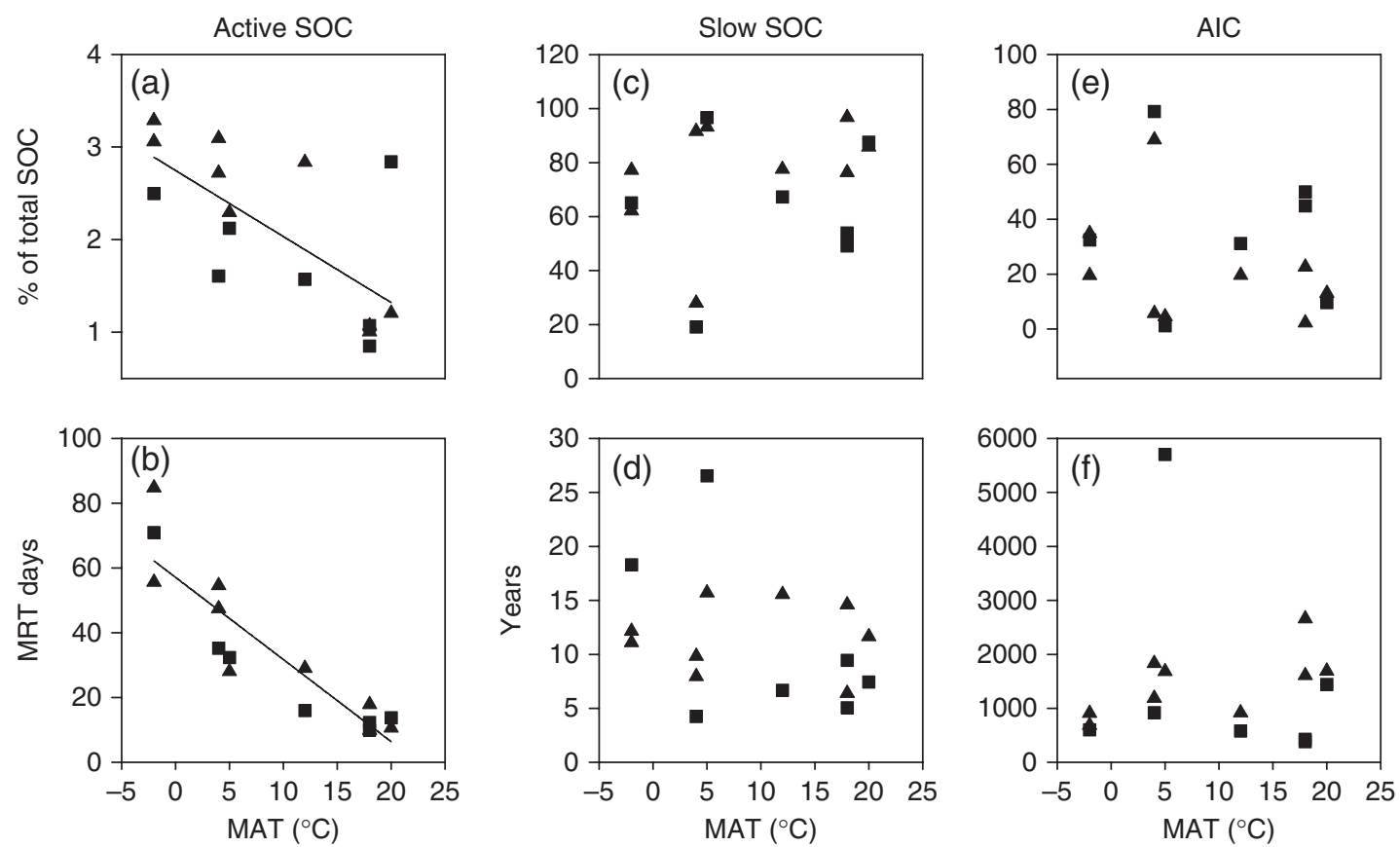

Fig. 1 Relationship between active, slow and acid insoluble SOC as isolated by the three-pool decomposition model and mean annual temperature (MAT) and mean residence time (MRT). In all panels, triangles represent pine stands and squares represent hardwood

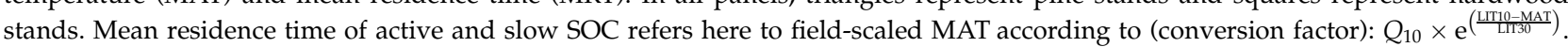
The effect of scaling MRT to field MAT did not affect the regression curves significantly. For instance, the effect of scaling reflects on the slope of the regression in $3 \mathrm{~b}$ but not on the significance of the relationship (MRT $=-2.3 \mathrm{MAT}+17.2 ; r^{2}=0.68, P<0.01 ; n=16$ ). SOC, soil organic carbon.

Table 4 Regression analysis of the three SOC fractions (Fig. 1) that describes the effect of mean annual temperature (MAT) on size of each fraction (as \% of total SOC) and mean residence time (MRT)

\begin{tabular}{|c|c|c|c|c|c|c|}
\hline SOC fraction & $x$ & $y$ & $n$ & Regression equation & $r^{2}$ & $P$ value \\
\hline Active & MAT & $\%$ of total SOC & 16 & $y=-0.07 x+2.75$ & 0.48 & $<0.05$ \\
\hline Active & MAT & MRT & 16 & $y=-2.54 x+57.11$ & 0.82 & $<0.01$ \\
\hline Slow & MAT & $\%$ of total SOC & 16 & $y=0.54 x+65.35$ & 0.04 & 0.48 \\
\hline Slow & MAT & MRT & 16 & $y=-0.22 x+13.50$ & 0.10 & 0.22 \\
\hline Acid insoluble & MAT & $\%$ of total SOC & 16 & $y=-0.47 x+31.91$ & 0.03 & 0.54 \\
\hline Acid insoluble & MAT & MRT & 16 & $y=-0.37+1454.25$ & $<0.01$ & 0.99 \\
\hline
\end{tabular}

SOC, soil organic carbon. 
represents MRT under field conditions, and integrates MAT, MAP, and substrate supply in the field over centuries. The proportion of total SOC that was AIC averaged 27\% across MAT (Table 3), and AIC \% increased with increasing total SOC. The size of the AIC fraction was variable but unrelated to MAT (Fig. 1e). Stepwise multiple linear regression analyses showed that only CEC was significantly related to AIC as a percent of total SOC (Fig. 2). AIC was unrelated to $\mathrm{pH}$, clay content, and vegetation type, which were excluded from the final model.

The MRT of AIC was 1451 year (Table 3), which was consistently longer than the MRT for total SOC in bulk soil (average MRT of total $\mathrm{SOC}=180$ years, $\mathrm{SE}=22$, $n=16)$. The long MRT for AIC at one MI site (5670 years) clearly influenced MRT for this fraction across MAT (see footnote in Table 3). Soil $\Delta{ }^{14} \mathrm{C}$ and radiocarbonbased estimates of MRT for AIC were unrelated to MAT (Fig. 1f, Table 4). Notably, $\Delta^{14} \mathrm{C}$ values were inversely but nonlinearly related to AIC content (Fig. 3). While $\Delta^{14} \mathrm{C}$ of total SOC was unrelated to clay content $\left(r^{2}=0.07\right.$, $P=0.32, n=16), \Delta^{14} \mathrm{C}$ of AIC was negatively related to clay content $\left(r^{2}=0.40, P<0.01, n=16\right)$ and both $\Delta^{14} \mathrm{C}$ and AIC MRT were unrelated to CEC.

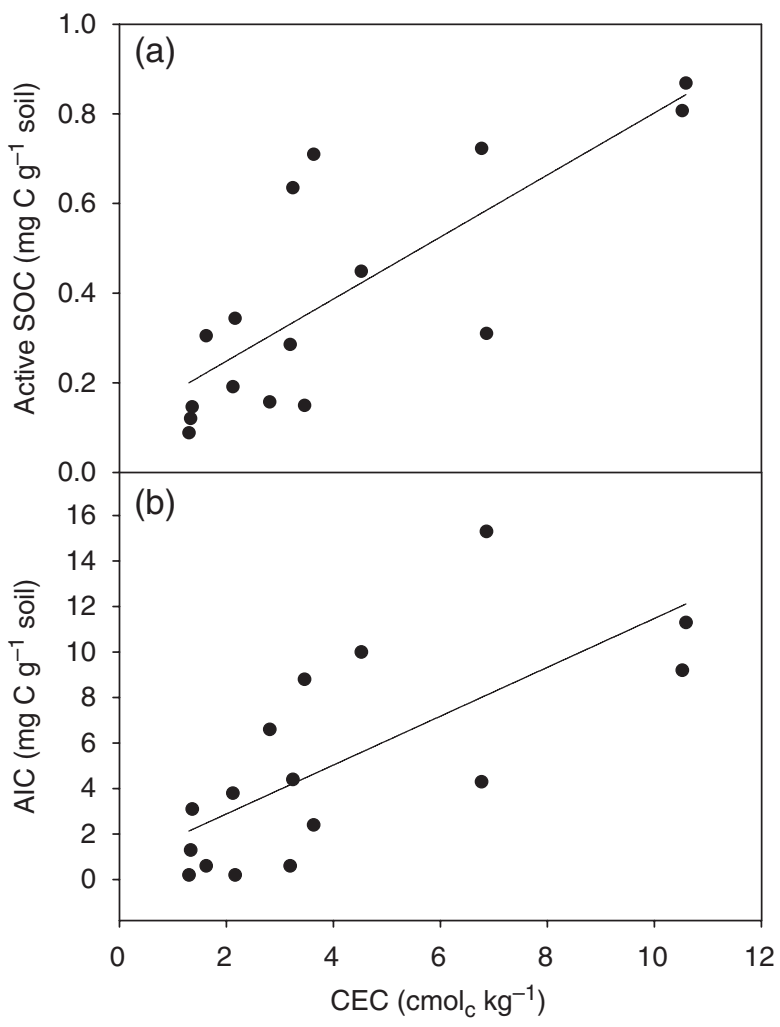

Fig. 2 Linear regressions showing the effect of CEC on (a) active SOC fraction $\left(r^{2}=0.56, P<0.01, n=16\right)$ and (b) acid insoluble C (AIC) content $\left(r^{2}=0.51, P<0.01, n=16\right)$. SOC, soil organic carbon; $\mathrm{CFC}$, cation exchange capacity.
Active C. The rate of $\mathrm{CO}_{2}$ efflux $\left(\mathrm{mgCg}^{-1}\right.$ initial soil $\mathrm{C}$ day $^{-1}$ ) from soils incubated at LIT30 decreased from $1.98( \pm 0.13$, mean $\pm \mathrm{SE}) \mathrm{mg} \mathrm{C} \mathrm{g}^{-1}$ soil C day $^{-1}$ at day 1 to $0.57( \pm 0.05) \mathrm{mg} \mathrm{C} \mathrm{g}^{-1}$ soil $\mathrm{C} \mathrm{day}^{-1}$ at day 22. A more muted pattern was observed at LIT10, where $\mathrm{CO}_{2}$ efflux rate declined from $0.38 \quad( \pm 0.02) \mathrm{mgC}^{-1}$ soilC day $^{-1}$ on day 1 to $0.25 \quad( \pm 0.02) \mathrm{mgC}^{-1}$ soil $\mathrm{Cday}^{-1}$ on day 22. In both cases, rates of respiration stabilized at low values in later stages of the incubation (Fig. 4a). The $\mathrm{CO}_{2}$ efflux rates $\left(\mu \mathrm{g} \mathrm{Cg}^{-1}\right.$ soilday ${ }^{-1}$ ) obtained from LIT30 on a subset of 16 soil samples were used to quantify the size and kinetics of active SOC according to a three-pool decomposition model (Paul et al., 2001, 2006) that utilizes curve fitting of the $\mathrm{CO}_{2}$ efflux data per soil sample throughout the incubation. According to this three-pool model, the proportion of active SOC ranged between 0.1 and $0.9 \mathrm{mg} \mathrm{C} \mathrm{g}^{-1}$ soil across sites, which represented between $0.9 \%$ and $3.3 \%$ of total SOC (Table 3 ) and was negatively related to MAT (Fig. 1a). The associated active SOC MRT varied across sites between 10 and 85 days, and was longer at cold than at warm sites (Fig. 1b). Among soil characteristics, only CEC was a good predictor of active SOC MRT $\left(r^{2}=0.56 ; P<0.01 ; n=16\right)$.

Slow C. The size of slow SOC fraction was estimated in the model by subtracting active plus AIC from total SOC. Slow SOC represented between $19 \%$ and $97 \%$ of total SOC (Table 3) and was unrelated to MAT (Fig. 1c). The MRT for slow SOC ranged between 4 and 27 year, and also was unrelated to MAT (Fig. 1d) or other soil characteristics. Exclusion of the single site with longer than average MRT did not significantly affect our results.

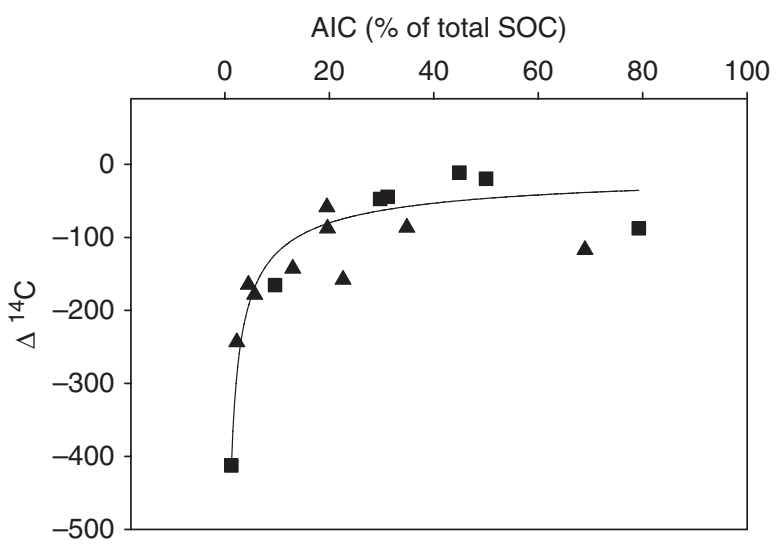

Fig. 3 Relative proportion of total SOC that is acid insoluble C (AIC) and correspondent values of $\Delta^{14} \mathrm{C}$. Triangles represent pine stands while squares represent hardwood stands. The equation for the nonlinear regression fit was: $\Delta{ }^{14} \mathrm{C}=-471.9$ (AIC \%) e $(-0.59)\left(r^{2}=0.94, P<0.01, n=16\right)$. SOC, soil organic carbon. 

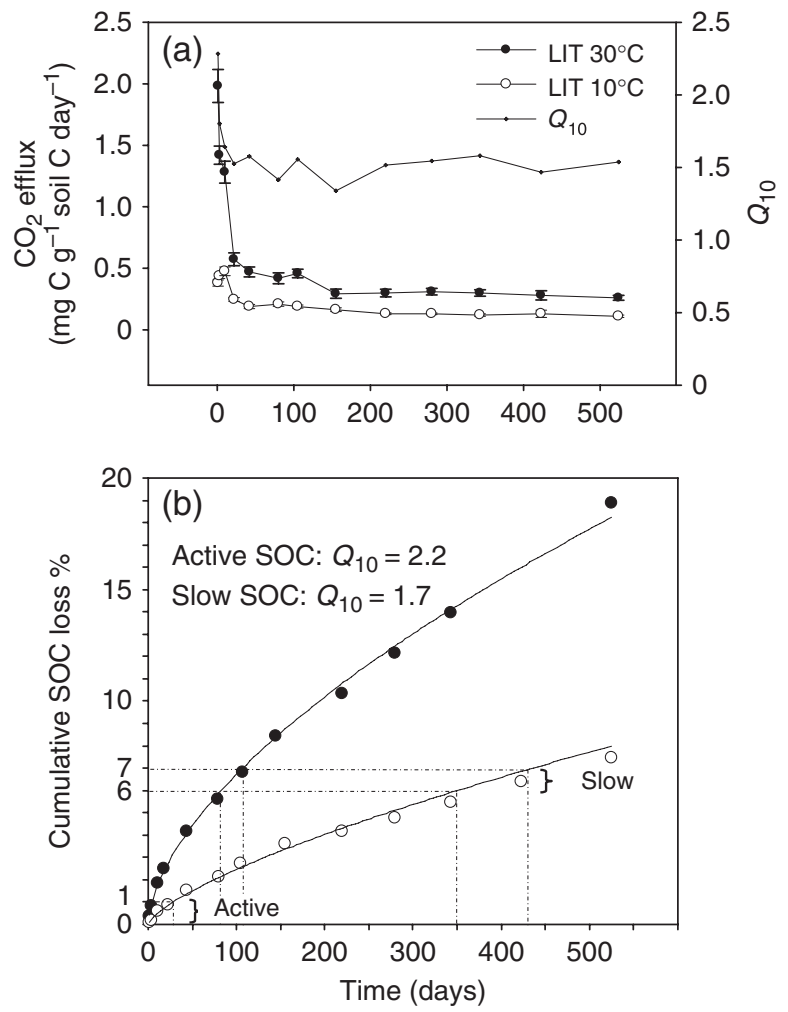

Fig. 4 (a) Carbon efflux rates and temperature sensitivity values $\left(Q_{10}\right)$ from soils incubated at 30 and $10{ }^{\circ} \mathrm{C}$ for 525 days. $Q_{10}$ was calculated by comparing $\mathrm{CO}_{2}$ efflux rates at 10 and $30^{\circ} \mathrm{C}$ at specific times during the incubation. (b) Cumulative SOC loss during the 525-day incubation at 30 and $10^{\circ} \mathrm{C}$. $Q_{10}$ in this case was calculated based on the time required at each LIT to decompose $1 \%$ of SOC. Specifically, active SOC $Q_{10}$ refers to the initial $1 \%$ of SOC being decomposed, while slow SOC $Q_{10}$ refers to the time required to decompose $1 \%$ of SOC after the decomposition of $6 \%$ of SOC. SOC, soil organic carbon; LIT, lab incubation temperatures.

Results from the two LITs were used also to calculate $Q_{10}$, which ranged between 2.3 and 1.6 (average $Q_{10}=$ $1.9 \pm 0.19$ ) during the initial 10 days of incubation, and stabilized to an average value of $1.5( \pm 0.02)$ for the remainder of the incubation (Fig. 4a). Different approaches have been proposed to calculate $Q_{10}$ that take into account the fact that after a certain amount of time, soils incubated at low LIT retain a higher amount of active SOC than similar soils incubated for the same amount of time at higher LIT (Conant et al., 2008). Across sites, we found similar results when $Q_{10}$ was calculated based on the time required for a certain amount of SOC to decompose at two different LITs (Conant et al., 2008). Specifically, $Q_{10}$ associated with the respiration of an initial $1 \%$ of SOC, which has been hypothesized to be representative of the active SOC fraction (Conant et al., 2008), was 2.2; $Q_{10}$ of the $1 \%$ SOC respired after the first $6 \%$ had been respired, indicative of the slow SOC

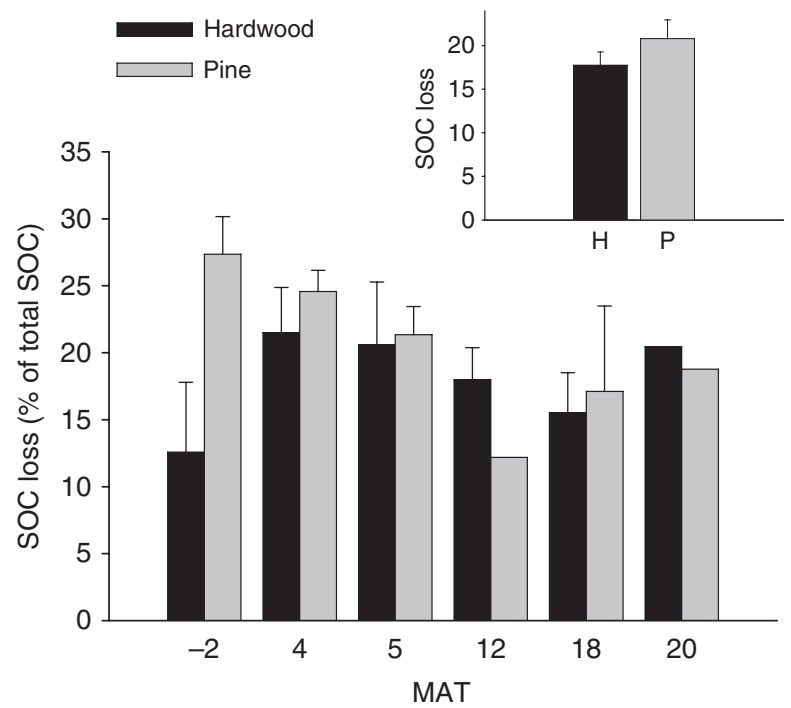

Fig. 5 Percent of total SOC lost during the 525-day incubation at $30^{\circ} \mathrm{C}$. Values are average per group of MAT + SE Regression analysis of these data showed $r^{2}=0.08, P=0.16, n=26$ for LIT30; $r^{2}<0.01, P=0.96, n=26$ for LIT10. The insert graph shows the overall average SOC loss $(+\mathrm{SE})$ across the MAT gradient for each vegetation type ( $n=15$ for hardwood, $n=11$ for pine). $t$-Test analysis showed no significant difference between hardwood and pine sites (overall and for each MAT) and this lack of significance was in some cases due to limited sample size. SOC, soil organic carbon; MAT, mean annual temperature; LIT, lab incubation temperatures.

fraction, was 1.7 (Fig. 4b). Calculated total cumulative SOC loss (as \% of total SOC) was significantly affected by LIT $(P<0.01, n=26)$, but not by MAT. While $C$ loss at LIT30 appeared to be more pronounced at cold sites than at warmer ones, especially in pine stands (Fig. 5), there was no significant relationship with MAT. Overall, the decline in $Q_{10}$ with incubation time matches the in situ, radiocarbon-based estimates of AIC MRT, which showed no significant relationship with MAT.

\section{SOC quality and forest type}

For pine soils, there was a weak but nonsignificant decline in $\Delta^{14} \mathrm{C}$ with increasing MAT $\left(r^{2}=0.33, P=\right.$ $0.10, n=9$ ), which suggests that MRT may actually increase with MAT. While not significant, this trend suggests that increased MAT does not result in reduced MRT for stable $C$ forms. In contrast, there was no relationship between MAT and MRT of AIC for hardwood stands (Fig. 1). Pine soils had proportionally less AIC compared with hardwood soils, but while pine soils had lower \% of AIC, the $\Delta^{14} \mathrm{C}$ values for pine AIC were more negative than those in hardwood stands (Fig. 3). There was one exception of a very negative $\Delta{ }^{14} \mathrm{C}$ value $\left(\Delta{ }^{14} \mathrm{C}=-412 \%\right)$ observed for $\mathrm{AIC}$ in the MI 
hardwood site (Table 3), which represented only $1.2 \%$ of total SOC. Overall, MRT of AIC was longer in pine than hardwood soils when this MI hardwood site was excluded (see footnote in Table 3).

During 525-days incubations at LIT30, there was a small difference in SOC loss (\% of total SOC derived from cumulative decomposition data) between pine and hardwood soils (Fig. 5). While the incubation showed weak evidence that MAT explained the variability in SOC loss (and hence the size of active SOC) in pine $\left(r^{2}=0.31, P=0.07, n=11\right)$, this relationship was better described when incubation data were plotted in a three-pool decomposition model.

The three-pool decomposition model showed no significant difference in the proportion (expressed as \% of total SOC) of active SOC between pine and hardwood, although pine soils had slightly more active SOC with longer MRT (Table 3). For both vegetation types there was significant decline in both proportion and MRT of active SOC with increasing MAT (Fig. 1a and b, Table 3). Specifically, MAT explained $82 \%$ and $84 \%$ of the variation in active SOC MRT in pine and hardwood soils, respectively. The proportion of slow to total SOC was similar in pine and hardwood across sites, with nearly identical MRT (Table 3).

\section{Discussion}

\section{SOC fractions across the MAT gradient}

The effects of warming on the net release of organic $C$ from soils to the atmosphere depend fundamentally on

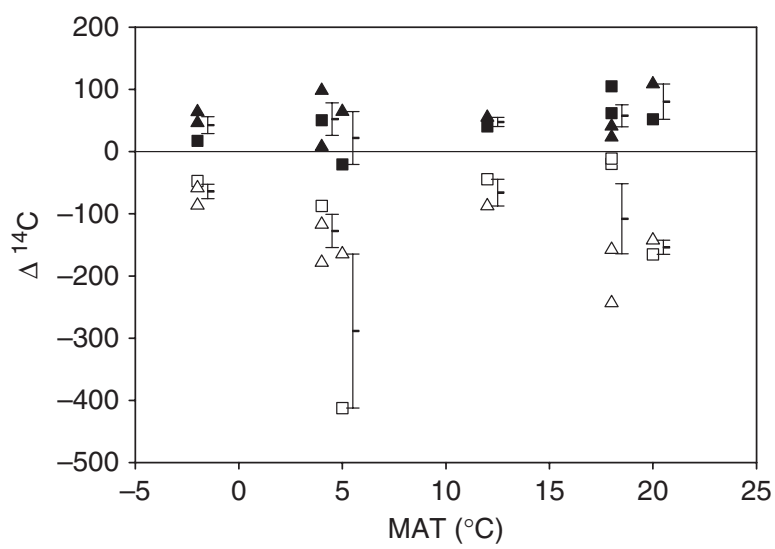

Fig. 6 Values of $\Delta^{14} \mathrm{C}$ of total and acid insoluble SOC for a subset of 16 soil samples across the MAT gradient. Triangles represent pine stands, squares represent hardwood stands. For each vegetation type, full symbols represent total SOC and open symbols acid insoluble C. For both total SOC and acid insoluble C, single-line symbols represent the average $\Delta^{14} \mathrm{C}( \pm \mathrm{SE})$ for each group of sites with similar MAT. Positive values of $\Delta^{14} \mathrm{C}$ indicates dominance of modern ${ }^{14} \mathrm{C}$, negative values of $\Delta{ }^{14} \mathrm{C}$ indicate dominance of older C. SOC, soil organic carbon; MAT, mean annual temperature. how temperature regulates the decomposition of stable SOC. In line with previous results (Townsend et al., 1997; Collins et al., 2000), our study shows that only a small fraction of total SOC is active ( $<3.5 \%$ in our study) with an MRT that was highly sensitive to temperature. In contrast, we found that the slow and AIC fractions make up a much larger proportion of total SOC with both showing much longer MRT that are much less sensitive or insensitive to MAT. These results support our initial hypothesis that SOC decomposition rates are less sensitive to changes in MAT than currently modeled, and support the view that for upland forests within our range of MAT, SOC losses in response to global warming will be less than predicted (Giardina \& Ryan, 2000).

Both the temperature sensitivity of active SOC and AIC and the methods used to estimate sensitivity are still highly debated. Calculation of temperature sensitivity of SOC fractions according to $\mathrm{CO}_{2}$ efflux rates at two given LITs has recently received some criticism in favor of an alternative approach based on the time required for a known amount of SOC to decompose (Conant et al., 2008). This latter approach has shown higher $Q_{10}$ for stable SOC in several grassland soils (Conant et al., 2008). However, similar calculations led to a different outcome in our study. We found substantially lower $Q_{10}$ for older than younger SOC regardless of how sensitivity was calculated (Fig. 4). That our findings are directly in line with earlier incubation studies (e.g., Winkler et al., 1996; Holland et al., 2000) indicates that methodology cannot explain the difference between studies. Instead, variation may derive from soil chemical differences including higher amounts of total and active SOC in grassland soils compared with forest soils. Critically, both calculation approaches focus on the temperature sensitivity of $<20 \%$ of total SOC that is lost during several hundred days of incubation. To examine the effects of MAT on the remaining $80 \%$ of total SOC, our combined fractionation and radiocarbon approach shows opposite trends in temperature sensitivity for active SOC and AIC fractions, with the MRT of the AIC fraction being weakly (pine) or not sensitive (hardwoods) to MAT. The use of fractionation techniques and radiocarbon analyses provides an in situ estimate of the size and MRT of AIC (i.e., SOC formation and loss under field conditions), and so integrates effects due to temperature, moisture, and priming that may be lost during longterm incubations due to a constant environment and elimination of labile C compounds inputs to soil (Dijkstra \& Weixin, 2007).

If temperature had a strong positive effect on the decomposition of stable SOC (Fang et al., 2005; Knorr et al., 2005), we would expect $\Delta{ }^{14} \mathrm{C}$ values for AIC 
fraction to be less negative at warm sites of our MAT gradient than at cold sites. In contrast, $\Delta{ }^{14} \mathrm{C}$ values for the slow and AIC fractions were unrelated or very weakly related to MAT (Fig. 6), with $Q_{10}$ values that ranged between 1 and 1.2 across MAT for these two fractions. Because the AIC fraction was ten times larger than the active $C$ fraction across forest soils, our findings suggest that generalizations from short-term incubations may provide a highly misleading view of SOC sensitivity to temperature.

These results are in line with the findings of Trumbore et al. (1996), who found that stable SOC was insensitive to MAT in contrast to high sensitivity reported for active SOC. Further, in a comparison of temperate and tropical soils, Six et al. (2002) observed that tropical soils accumulate a greater proportion of SOC that is more stable compared with temperate soils. In the case of pine soils, our results suggest higher rates of SOC stabilization with increasing MAT. These collective findings support the hypothesis proposed by Thornley \& Cannell (2001), who postulated stabilization of SOC is promoted at warm temperatures despite the positive effect of temperature on litter decomposition.

In soils rich in $\mathrm{Al}$ and $\mathrm{Fe}$ oxides (i.e., highly-weathered soils more typical of warmer sites) SOC stabilization may be further accentuated because of aggregation and complexation processes (Dalal, 2001; Jastrow et al., 2007). Similarly, greater SOC stabilization also has been hypothesized for fine-textured soils (Nichols, 1984), but the extent of this effect on SOC fractions across clay content is still not clear. In line with our findings, previous studies have shown mixed results between soil texture and SOC content (Percival et al., 2000; Plante et al., 2006) or decomposition rates (Giardina \& Ryan, 2000; Giardina et al., 2001). Further, changes in mineralogy (shifts from high charge density clays to low charge density clays) and chemistry (lower $\mathrm{pH}$ and CEC) may exert opposing effects on SOC content and decomposition rates (Fissore et al., 2008).

Both the physical-chemical association of SOC with the mineral matrix (Jastrow et al., 2007; Rasmussen et al., 2007) and the specific exchange properties of the mineral phase affect SOC stabilization (Torn et al., 1997; Kleber et al., 2007). Across our field sites, the limited range of clay content of our soils did not correspond to a limited range in mineralogy, and the observed wide differences in clay mineral composition (Fissore et al., 2008) may in part explain variation in MRT across SOC fractions. Several lines of evidence indicate that mineralogy is a better predictor of SOC stabilization than soil texture alone (Torn et al., 1997; Rasmussen et al., 2006). To this end, we observed that the content of both AIC and active SOC was positively related to CEC, which is indicative of the negative charge of the mineral phase.
This supports the view that a portion of active SOC also can be stabilized by clay minerals in the presence of exchangeable sites (Sørensen, 1972; Mikutta et al., 2006). While CEC - and hence the mineral phase - contributes to SOC stabilization, the mechanisms and interactions involved remain unclear (Ågren \& Wetterstedt, 2007; Sollins et al., 2007) and that these mechanisms may have different effects on the MRT of AIC and active SOC.

Both MAT and CEC were good predictors of active SOC MRT, with longer MRT observed at cold sites where both lower temperature and higher CEC could contribute to higher stabilization rates. The AIC fraction showed a different pattern, with ${ }^{14} \mathrm{C}$-based MRT of AIC being inversely related to the fraction of total SOC that was acid insoluble (Fig. 3). At the same time, AIC, as a percent of total SOC, increased with CEC, but MRT of the AIC fraction was not related to CEC. We speculate that less SOC is stabilized when few binding sites are available because of low clay content or clay with limited surface charge, but this SOC is more resistant to degradation, resulting in longer MRT. Conversely, abundance of reactive surface charges and other binding characteristics of the mineral phase can stabilize SOC across a wide range of MRT through cation bridging of negatively charged organic groups, interactions with hydrous oxides and $\mathrm{Al}$ and $\mathrm{Fe}$ groups and other organominerals interactions (Oades, 1988). For these reasons, reduced SOC decomposition in presence of highly charged clay minerals occurs across soil types (Torn et al., 1997; Rasmussen et al., 2006, 2007) and involves both labile and recalcitrant organic compounds (Jastrow et al., 2007).

Across large scales, MAT and mineralogy ultimately may be useful parameters in predicting the size and MRT of different SOC fractions and may help explain the observed divergence among short-term laboratory studies and long-term field studies. Critically, if substrate supply controls the influence of temperature on soil $\mathrm{C}$ decomposition rates, then cold climate soils or currently water-logged soils, where soil C substrate supply is high, may release more $C$ than anticipated from standard model $Q_{10}$ values (Giardina \& Ryan, 2000; Davidson \& Janssens, 2006).

Previous studies have found stable SOC to be either a small (Trumbore et al., 1996) or large (Paul et al., 2001) fraction of total SOC across sites in North America. We suggest that differences in vegetation type, soil, and site characteristics may explain this apparent discrepancy. Paul et al. (2001) found that approximately $50 \%$ of total SOC is stable in mixed hardwood forests, consistent with our findings for several hardwood soils sharing similar bioclimatic regions. Finer-textured soils may explain the slightly higher MRT found by Paul et al. (2001) where greater clay content and CEC might have 
contributed to higher rates of SOC stabilization. In contrast, Trumbore et al. (1996) reported that stable SOC accounted for $15 \%$ or less of total SOC in coarsetextured oak and pine sites. In line with these findings, AIC accounted for $20 \%$ or less of total SOC for the majority of our pine sites. The 12-year time span between soil sampling and analysis in our study and the study of Paul et al. (2001) and Trumbore et al. (1996) prevents us from making direct radiocarbon comparisons. However, our results do suggest that conclusions about the distribution of SOC fractions and sensitivity to a changing climate appear to depend strongly on the sites selected.

The presence of a very old (5670 years) AIC at one of our sandy soils from Michigan is unusual, considering the shallow depth: previous findings of a 13000 old nonhydrolysable fraction were for a deep horizon soil from Wisconsin (Paul et al., 2001). A combination of factors, including SOC chemical recalcitrance, soil texture, and soil depth may contribute to the stabilization of extremely old SOC. However, the relative importance of these factors for surface soils remains uncertain, and may or may not explain the long MRT of the AIC in this Michigan soil sample.

\section{SOC fractions and MRT in relation to forest type}

The interaction between plant species composition and microbial communities is hypothesized to affect ecosystem processes such as $\mathrm{C}$ and nutrient cycling across ecosystems (Hobbie, 1992; Binkley \& Giardina, 1998; Lorenz et al., 2007). In the long-term, climate change may also affect $\mathrm{C}$ allocation belowground (Litton \& Giardina, 2008) as well as changes in tree species composition that together with allocation can affect SOC formation and storage (Giardina et al., 2005). We found that the effects of tree species were more complex than we originally hypothesized. Our results suggest that the active and slow $C$ fractions in our pine forest soils have a shorter MRT than in the paired hardwood forest soils. Also in line with our hypotheses, these pine soils store a smaller AIC fraction than hardwood forest soils, although this fraction appears to be older. In a subtropical study examining natural mixed forests and pine plantations, differences in SOC fractions have been related to changes in litter chemistry, with a vegetation conversion into a plantation resulting in a decrease in total SOC and a $17.7 \%$ decrease in water-soluble organic C (Chen et al., 2004). In temperate forests in North America, SOC accumulated at a greater rate in hardwood than conifer stands (Morris et al., 2007), whereas at high latitude sites, active SOC content was found to be lower in hardwood than pine soils (Smolander \& Kitunen, 2002). Terrestrial ecosystem models incorpo- rate a strong control of litter chemistry on long-term SOC stabilization, but effects of initial litter chemistry, such as lignin: $\mathrm{N}$ and lignin concentration, on litter decomposition may disappear after just a few years (Prescott et al., 2004) or even reverse in the long-term (sensu Berg \& Meentemeyer, 2002). The concomitant effects of climate and litter chemistry on litter and SOC decomposition likely affect SOC accumulation and MRT across forest types, but our understanding of the mechanisms involved is far from complete. For example, the relationship between belowground litter quality and quantity and aboveground litter quality and quantity and their relative contributions to SOC formation remain poorly quantified.

In our study, a larger fraction of total SOC was active in pine forest soils, and in both pine and hardwood soil the decomposition of active SOC increased with increasing MAT, probably because of greater $\mathrm{C}$ accumulation and slower decomposition of active $\mathrm{C}$ at cold sites. This finding suggests that all else being equal, if MAT increases, greater losses of active SOC will occur from pine forests than hardwood soils and overall this loss will be greater in cold ecosystems. In contrast, AIC accumulation was greater in hardwood than pine sites, and modeled SOC decomposition rates were independent of MAT. These findings suggest that for our coarse texture soils, MAT is a driver of active SOC decomposition but not of AIC. This finding also supports the view that initial decomposition is related to climatic conditions across extended geographical areas (Liski et al., 2003), but that other factors such as soil structure, texture, and mineralogy affect long-term SOC stabilization across forest types.

Higher clay content in hardwood than pine soils (Fissore et al., 2008) could explain vegetation-type differences in total SOC. One could argue that the effect of clays may have obscured the effect of vegetation not only for SOC accumulation but also for SOC stabilization. Rasmussen et al. (2007) found that SOC stabilization was related to the mineral assemblage in various conifer stands, with greater stabilization occurring in the presence of highly charged minerals. Across forest types in our study, CEC did not predict MRT of AIC. Conversely, the MRT of active SOC was positively related to CEC. The complex potential interactions between mineral assemblage and vegetation type clearly need further investigation, and highlight the difficulty of identifying trends from naturally occurring stands compared with common garden type studies (Binkley \& Giardina, 1998; Hobbie et al., 2006).

Microbial community function and structure also likely contributes to differences in SOC quality and decomposition across our sites, though we have not yet addressed this potential source of variation. Pre- 
sence of fungal communities specialized in decomposition of low quality substrates may be responsible for limited accumulation of stable SOC in conifer soils (Giardina et al., 2001). In contrast, the microbial communities generally found in hardwood forests preferentially decompose active $\mathrm{C}$ substrates, leaving behind more stable compounds. Recent studies have pointed to the complexity of the processes involved in SOC stabilization and to the importance of biologically derived $\mathrm{C}$ compounds in forming stable SOC (Lorenz et al., 2007; von Lützov et al., 2007). However, microbial factors are likely to covary with vegetation, soil and site characteristics, complicating interpretation of findings. As changes in tree and forest ecosystems distribution have been predicted as a consequence of climate change (Hughes, 2000; Hansen et al., 2001), our results, which integrate these covarying factors, suggest that SOC stabilization will also be modified. Clearly, interactions with other ecological variables such as moisture (Davidson \& Janssens, 2006), atmospheric pollutants (Loya et al., 2003), or altered allocation patterns (Litton \& Giardina, 2008) may have dominant affects on belowground processes, and so will be important to consider in the next generation of terrestrial ecosystem models.

\section{Acknowledgements}

This research was funded by the Northern, Southern and Pacific Southwest Research Stations of USDA Forest Service. We thank Wendy Loya for help with C fractionation techniques, Margaret Torn for her support and insights on the application of radiocarbon techniques, and Tom Guilderson, Cristina Castana, Paula Zermeno, and Rachel Porras for assisting with sample preparation and radiocarbon analysis. We thank Christopher Barton and Carl Trettin for helping with logistics and soil sampling in $\mathrm{KY}$ and SC, and Jennifer Eikenberry and Noah Karberg for support with GC work. We also thank Melissa Porter and Christa Luokkala for their lab work. Finally, we thank three anonymous reviewers for their insightful comments.

\section{References}

Ågren GI, Wetterstedt JÅM (2007) What determines the temperature response of soil organic matter decomposition? Soil Biology and Biochemistry, 39, 1794-1798.

Barriuso E, Portal JM, Andreux F (1987) Kinetics and acid hydrolysis of organic matter in humic-rich mountain soil. Canadian Journal of Soil Science, 67, 647-658.

Berg B (2000) Litter decomposition and organic matter turnover in northern forest soils. Forest Ecology and Management, 133, 13-22.

Berg B, Meentemeyer V (2002) Litter quality in a north European transect versus carbon storage potential. Plant and Soil, 242, 83-92.

Binkley D, Giardina CP (1998) Why do tree species affect soils? The Warp and Woof of tree-soil interactions. Biogeochemistry, 42, 89-106.
Chen CR, Xu ZH, Mathers NJ (2004) Soil carbon pools in adjacent natural and plantation forests of subtropical Australia. Soil Science Society of America Journal, 68, 282-291.

Collins HP, Elliott ET, Paustian K et al. (2000) Soil carbon pools and fluxes in long-term corn belt agroecosystems. Soil Biology and Biochemistry, 32, 157-168.

Conant RT, Drijber RA, Haddix ML et al. (2008) Sensitivity of organic matter decomposition to warming varies with its quality. Global Change Biology, 14, 1-10.

Dalal RC (2001) Acidic soil pH, aluminum and iron affect organic carbon turnover in soil. NEE Workshop Proceedings, 18-21.

Dalias P, Anderson JM, Bottner P, Coûteaux MM (2001) Temperature responses of carbon mineralization in conifer forest soils from different regional climates incubated under standard laboratory conditions. Global Change Biology, 6, 181-192.

Davidson EA, Janssens IA (2006) Temperature sensitivity of soil carbon decomposition and feedbacks to climate change. Nature, 440, 165-173.

Dijkstra FA, Weixin C (2007) Interactions between soil and tree roots accelerate long-term soil carbon decomposition. Ecology Letters, 10, 1046-1053.

Elliott ET, Burke IC, Monz CA et al. (1994) Terrestrial carbon pools: Preliminary data from the Corn Belt and Great Plains regions. In: Defining Soil Quality for a Sustainable Environment (eds Doran JW, Coleman DC, Bezdicek DF, Stewart BA), pp. 179-191. American Society of Agronomy, Madison.

Fan S, Gloor M, Mahlman J, Pacala S, Sarmiento J, Takahashi T, Tans P (1998) A large terrestrial carbon sink in north America implied by atmospheric and oceanic carbon dioxide data and models. Science, 282, 442-446.

Fang C, Smith P, Moncrieff JB, Smith JU (2005) Similar response of labile and resistant soil organic matter pools to changes in temperature. Nature, 433, 57-59.

Fissore C, Giardina CP, Kolka R et al. (2008) Temperature and vegetation effects on soil organic carbon quality along a forested mean annual temperature gradient in North America. Global Change Biology, 14, 193-205.

Fog K (1988) The effect of added nitrogen on the rate of decomposition of organic matter. Biological Review, 63, 433-462.

Gaudinski JB, Trumbore SE, Davidson EA, Zheng S (2000) Soil carbon cycling in a temperate forest: radiocarbon-based estimates of residence times, sequestration rates and partitioning of fluxes. Biogeochemistry, 51, 33-69.

Giardina CP, Coleman M, Hancock JE et al. (2005) The effects of global change on belowground carbon allocation in forests. Chapter 7. In: The Impacts of Global Climate Change on Plant Soil Interactions (eds Binkley D, Menyailo O), pp. 119-154. NATO Science Series, Kluwer Academic Press, Springer, the Netherland.

Giardina CP, Ryan MG (2000) Evidence that decomposition rates of organic carbon in mineral soil do not vary with temperature. Nature, 404, 858-861.

Giardina CP, Ryan MG, Hubbard RM, Binkley D (2001) Tree species and soil texture controls on carbon and nitrogen mineralization rates. Soil Science Society of America Journal, 65, 1272-1279.

Haile-Mariam S, Cheng W, Johnson DW, Ball JT, Paul EA (2000) Use of carbon-13 and carbon-14 to measure the effects of 
carbon dioxide and nitrogen fertilization on carbon dynamics in Ponderosa pine. Science Society of America Journal, 64, 1984-1993.

Hansen AJ, Neilson RR, Dale VH et al. (2001) Global change in forests: responses of species, communities, and biomes. Bioscience, 51, 765-779.

Hobbie SE (1992) Effects of plant species on nutrient cycling. Trends in Ecology and Evolution, 7, 336-339.

Hobbie SE, Reich PB, Oleksyn J, Ogdahl M, Zytkowiak R, Hale C, Karolewski P (2006) Tree species effects on decomposition and forest floor dynamics in a common garden. Ecology, 87, 2288-2297.

Holland EA, Neff JC, Townsend AR, McKeown B (2000) Uncertainties in the temperature sensitivity of decomposition in tropical and subtropical ecosystems: implications for models. Global Biogeochemical Cycles, 14, 1137-1151.

Hughes L (2000) Biological consequences of global warming: is the signal already apparent? Trends in Ecology and Evolution, 15, $56-61$.

Ise T, Moorcroft PR (2006) The global-scale temperature and moisture dependencies of soil organic carbon decomposition: an analysis using a mechanistic decomposition model. Biogeochemistry, 80, 217-231.

Jastrow JD, Amonette JE, Bailey VL (2007) Mechanisms controlling soil carbon turnover and their potential application for enhancing carbon sequestration. Climatic Change, 80, 5-23.

Jenkinson DS, Adams DE, Wild A (1991) Model estimates of $\mathrm{CO}_{2}$ emissions from soil in response to global warming. Nature, 351, 304-306.

Jobbagy EG, Jackson RB (2000) The vertical distribution of soil organic carbon and its relation to climate and vegetation. Ecological Applications, 10, 423-436.

Kleber M, Sollins P, Sutton R (2007) A conceptual model of organo-mineral interactions in soils: self-assembly of organic molecular fragments into zonal structures on mineral surfaces. Biogeochemistry, 85, 9-24.

Knorr W, Prentice IC, House JI, Holland EA (2005) Long-term sensitivity of soil carbon turnover to warming. Nature, 433, 298-301.

Leavitt SW, Follett RF, Paul EA (1997) Estimation of slow and fast cycling soil organic carbon pools from $6 \mathrm{~N} \mathrm{HCl}$ hydrolysis. Radiocarbon, 38, 231-239.

Liski J, Nissinen ARI, Erjard M, Taskinen O (2003) Climatic effects on litter decomposition from arctic tundra to tropical rainforest. Global Change Biology, 9, 575-584.

Litton CM, Giardina CP (2008) Belowground carbon flux and partitioning: global patterns and response to temperature. Journal of Functional Ecology, 22, 941-954.

Lorenz K, Lal R, Preston CM, Nierop KGJ (2007) Strengthening the soil organic carbon pool by increasing contributions from recalcitrant aliphatic bio(macro)molecules. Geoderma, 142, 1-10.

Loya WM, Pregitzer KS, Karberg NJ, King JS, Giardina CP (2003) Reduction of soil carbon formation by tropospheric ozone under elevated carbon dioxide. Nature, 425, 705-707.

Magill AH, Aber JD, Hendricks JJ, Bowden RD, Melillo JM, Steudler PA (1997) Biochemical responses of forest ecosystems to simulated chronic nitrogen deposition. Ecological Applications, 7, 402-415.
McLauchlan KK, Hobbie SE (2004) Comparison of labile soil organic matter fractionation techniques. Soil Science Society of America Journal, 68, 1616-1625.

Melillo JM, Aber JD, Linkins AE, Ricca A, Fry B, Nadelhoffer KJ (1989) Carbon and nitrogen dynamics along the decay continuum: plant litter to soil organic matter. Plant and Soil, 115, 189-198.

Melillo JM, Aber JD, Muratore JF (1982) Nitrogen and lignin control of hardwood leaf litter decomposition dynamics. Ecology, 63, 621-626.

Mikutta R, Klaus M, Torn M, Jahn R (2006) Stabilization of soil organic matter: association with minerals or chemical recalcitrance? Biogeochemistry, 77, 25-56.

Morris S, Bohm S, Haile-Mariam S, Paul EA (2007) Evaluation of carbon accrual in afforested agricultural soils. Global Change Biology, 13, 1145-1156.

Nichols JD (1984) Relation of organic carbon to soil properties and climate in the Southern Great Plains. Soil Science Society of America Journal, 48, 1382-1384.

Oades JM (1988) The retention of organic matter in soils. Biogeochemistry, 5, 35-70.

Paul EA, Clark FE (1996) Soil Microbiology and Biochemistry, 2nd edn. San Diego, CA.

Paul EA, Morris SJ, Böhm S (2001) The determination of soil C pool sizes and turnover rates: biophysical fractionation and tracers. In: Assessment Methods for Soil Carbon (eds Lal R et al.), pp. 193-205. Lewis Publications, Boca Raton, FL.

Paul EA, Morris SJ, Conant RT, Plante AF (2006) Does the acid-hydrolysis incubation method measure meaningful soil organic carbon pools? Soil Science Society of America Journal, 70, 1023-1035.

Percival HJ, Parfitt RL, Scott NA (2000) Factors controlling soil carbon levels in new zealand grasslands: is clay content important? Soil Science Society of America Journal, 64, 1623-1630.

Plante AF, Conant RT, Stewart CE, Paustian K, Six J (2006) Impact of soil texture on the distribution of soil organic matter in physical and chemical fractions. Soil Science Society of America Journal, 70, 287-296.

Prescott CE, Vesterdal L, Preston CM, Sima SW (2004) Influence of initial chemistry on decomposition of foliar litter in contrasting forest types in British Columbia. Canadian Journal of Forest Research, 34, 1714-1729.

Prescott CE, Zabek LM, Staley CL, Kabzems R (2000) Decomposition of broadleaf and needle litter in forests of British Columbia: influences of litter type, forest type and litter mixtures. Canadian Journal of Forests Research, 30, 1742-1750.

Quideau SA, Chadwick OA, Trumbore SE, Johnson-Maynard JL, Graham RC, Anderson MA (2001) Vegetation control on soil organic matter dynamics. Organic Geochemistry, 32, 247-252.

Rasmussen C, Southard RJ, Horwath WR (2006) Mineral control of organic carbon mineralization in a range of temperate conifer forest soils. Global Change Biology, 12, 834-847.

Rasmussen C, Southard RJ, Horwath WR (2007) Soil mineralogy affects conifer forest soil carbon source utilization and microbial priming. Soil Science Society of America Journal, 71, 1141-1150.

Rovira P, Vallejo VR (2002) Labile and recalcitrant pools of carbon and nitrogen in organic matter decomposition at different 
depths in soil: an acid hydrolysis approach. Geoderma, 107, 109-141.

Russell AE, Raich JW, Valverde-Barrantes OJ, Fisher RF (2007) Tree species effects on soil properties in experimental plantations in tropical moist forest. Soil Science Society of America Journal, 71, 1389-1397.

Schimel DS, Braswell BH, Holland EA et al. (1994) Climatic, edaphic, and biotic controls over storage and turnover of carbon in soil. Global Biogeochemical Cycles, 8, 279-293.

Six J, Feller C, Denef K, Ogle SM, de Moraes Sa JC, Albrecht A (2002) Soil organic matter, biota and aggregation in temperate and tropical soils - effect of no-tillage. Agronomie, 22, 755-775.

Smolander A, Kitunen V (2002) Soil microbial activity and characteristics of dissolved organic $\mathrm{C}$ and $\mathrm{N}$ in relation to tree species. Soil Biology and Biochemistry, 34, 651-660.

Sollins P, Swanston C, Kramer M (2007) Stabilization and destabilization of soil organic matter - a new focus. Biogeochemistry, 85, 1-7.

Sørensen LH (1972) Stabilization of newly formed amino-acid metabolites in soil by clay minerals. Soil Science, 114, 5-11.

Stuiver M, Polach HA (1977) Reporting of C-14 data. Radiocarbon, 19, 355-363.

Swanston C, Homann P, Caldwell B, Mrold DD, Ganio L, Sollins $P$ (2004) Long-term effects of elevated nitrogen on forest soil organic matter stability. Biogeochemistry, 70, 227-250.

Sykes MT, Prentice IC (1996) Climate change, tree species distributions and forest dynamics: a case study in the mixed conifer/northern hardwoods zone of northern Europe. Climatic Change, 34, 161-177.

Thornley JHM, Cannell MGR (2001) Soil carbon storage responses to temperature: an hypothesis. Annals of Botany, 87, 591-598.

Torn MS, Lapeni AG, Timofeev A, Fisher ML, Babikov BV, Harden JW (2002) Organic carbon and carbon isotopes in modern and 100-year-old-soil archives of the Russian steppe. Global Change Biology, 8, 941-953.

Torn MS, Trumbore SE, Chadwick OA, Vitousek PM, Hendricks DM (1997) Mineral control of soil organic carbon storage and turnover. Nature, 389, 170-173.
Townsend AR, Vitousek PM, Desmarais DJ, Tharpe A (1997) Soil carbon pool structure and temperature sensitivity inferred using $\mathrm{CO}_{2}$ and ${ }^{13} \mathrm{CO}_{2}$ incubation fluxes from five Hawaiian soils. Biogeochemistry, 38, 1-17.

Townsend AR, Vitousek PM, Trumbore SE (1995) Soil organic matter dynamics along gradients in temperature and land use on the island of Hawaii. Ecology, 76, 721-733.

Trumbore SE, Chadwick OA, Amundson R (1996) Rapid exchange between soil carbon and atmospheric carbon dioxide driven by temperature change. Science, 272, 393-396.

Trumbore SE, Davidson EA, de Camargo PB, Nepstad DC, Martinelli LA (1995) Belowground cycling of carbon in forests and pastures of Eastern Amazonia. Global Biogeochemical Cycles, 9, 515-528.

Vogel JS (1992) A rapid method for preparation of biomedical targets for AMS. Radiocarbon, 34, 344-350.

Vogel JS, Southon JR, Nelson DE, Brown TA (1984) Performance of catalytically condensed carbon for use in accelerator massspectrometry nuclear instrumentation methods. Physical Reviews, Section B Beam Interaction Material Atoms, 233, 289-293.

von Lützov $M$, Kögel-Knabner I, Ekschmitt $K$, Flessa $H$, Guggenberger G, Matzner E, Marschner B (2007) SOM fractionation methods: relevance to functional pools and to stabilization mechanisms. Soil Biology and Biochemistry, 39, 2183-2207.

von Lützov M, Kögel-Knabner I, Ekschmitt K, Matzner E, Guggenberger G, Marschner B, Flessa H (2006) Stabilization of organic matter in temperate soils: mechanisms and their relevance under different soil conditions - a review. European Journal of Soil Science, 57, 426-445.

Wedin DA, Pastor J (1993) Nitrogen mineralization dynamics in grass monocultures. Oecologia, 96, 186-192.

Winkler JP, Cherry RS, Schlesinger WH (1996) The $Q_{10}$ relationship of microbial respiration in a temperate forest soil. Soil Biology and Biochemistry, 28, 1067-1072.

Xu C, Gertner GZ, Scheller RM (2007) Potential effects of interaction between $\mathrm{CO}_{2}$ and temperature on forest landscape response to global warming. Global Change Biology, 13, 1-15. 